the publick Schools, though I understood them not at all at that Time. . . . We at Cambridge, poor Wretches, were ignominiously studying the fictitious Hypotheses of the Cartesian, which Sir Isaac Newton had also himself done formerly, as I have heard him say. What the Occasion of Sir Isaac Newton's leaving the Cartesian Philosophy, and of discovering his amazing Theory of Gravity was, I have heard him long ago, soon after my first Acquaintance with him, which was 1694 , thus relate, ..."

Then follows an account of incidents during Newton's life at Woolsthorpe when he retired from Cambridge owing to the plague. Doubt has been cast on some details of this story. But it is corroborated in all essentials not only by Pemberton but also by an account left by Newton himself. There can be no doubt that it represents a story which Newton was rather fond of telling in his old age. If therefore any doubt is to be entertained as to its accuracy, that must be attributed to the failing memory of an old man. It does not seem impossible that some picturesque details have accrued in the course of years.

That is not the present point of interest. If according to this account Newton ever flirted with the Cartesian philosophy, that must have been during his undergraduate days. That at some time Newton must have studied "the fictitious Hypotheses of the Cartesian" is one of Whiston's essays in the obvious. As the protagonist of a system of natural philosophy which found its greatest obstacle in the hypotheses of Des Cartes, Newton could scarcely have failed to do so. But the attitude of complete antagonism was established at least as early as 1666 (aet. 23).

But Whiston was twenty-five years younger than Newton, whom he succeeded in the Lucasian chair at Cambridge in 1703. The year in which he took deacon's orders was 1693. Thus the years of which he is speaking, when the Cartesian philosophy was alone in vogue at Cambridge, was at least six years after the publication of the "Principia", and not very long before Newton left Cambridge for London. It appears then that whatever impression the "Principia" may have created outside Cambridge, inside Cambridge the teaching of Newton had been practically without any effect whatever.

At no time had Newton a gift for friendship. But that in itself is no reason why he should not have enjoyed the active support of discerming men. This he had, from Halley in the greatest measure, but also from others. David Gregory (nephew of James), the Savilian professor of astronomy, adopted the Newtonian philosophy from the first. When the controversy with Leibniz assumed an unpleasant aspect, it was to John Keill, another Savilian professor, that Newton turned as his champion. Locke wrote: "I have several reasons to think him truly my friend". Now all these were Oxford men. Even Henry Pemberton, the editor of the third edition of the "Principia", was introduced to Newton by Keill ; he was not a Cambridge man. Robert Boyle, another acquaintance in correspondence with Newton, was a member of the group of men living in Oxford who founded the Royal Society.

It is inevitable that a comparison should be made with Newton's environment at Cambridge. If Newton sought no friends, it would still be supposed that some men of parts would seek his intellectual aequaintance. There is little evidence of it. Barrow resigned the Lucasian professorship in favour of
Newton in 1669, became Master of Trinity in 1673 and died in 1677 . That must have been a great loss to Newton. Whiston (of Clare Hall) made his acquaintance as related by himself, and Bentley cultivated it too, but philosophy rather than science was the common bond. This was only a few years before Newton left Cambridge; when Bentley became Master of Trinity (1700), Newton was established in London. But Bentley's account of the state of the College proves that Newton must have found it an utterly uncongenial environment. The impact of the Restoration on an academic community had been disastrous. At the same time Whiston's evidence goes to show that Newton was out of sympathy with the general trend of thought in the University of Cambridge at large.

These circumstances seem to explain much; why, for example, Newton was so ready to leave his quiet academic seclusion for the crowded life of the metropolis. It is just possible that Trinity was not so very quiet, while London and the Royal Society offered intellectual society far more to his taste. There is another aspect of the matter. In spite of Bentley's reforming zeal, which did produce fruit in a notable band of scholars, such as Porson, Cambridge in the eighteenth century, and Oxford too for that matter, failed conspicuously to take advantage of the opportunities opened up by Newton. An excuse has often been found in the notation (or absence of notation) of the fluxional calculus when contrasted with the methods of Leibniz. This seems hard to believe. Had there been a school of mathematicians, of the calibre of Colin Maclaurin for example, it is impossible to conceive that a mere question of notation would have been allowed to remain an obstacle when the successes of Clairaut and Euler were fairly considered. They did not receive this consideration because the men capable of giving it did not exist. The best English mathematicians of the period, like Simpson, Hutton and Peter Barlow, who were all connected with the Military Academy at Woolwich, owed nothing to university education.

1 Cf. Zinner, E., “Leben und Wirken des Johannes Müller von Königs berg genannt Regiomontanus" (Munich, 1938).

2 Pingré, “Annales Célestes du XVIIe Siecle”, p. 359 (1901).

s Birch, "History of the Royal Society", 4 (1757).

- Phil. Trans., No. 297, pp. 1882-99 (March, 1705).

s Whiston's Memoirs, 1, 35 (1749) : Rouse Ball, "Fssay on Principia" p. 8 .

\section{SOME BIOLOGICAL DISCOVERIES OF PRACTICAL IMPORTANCE*}

\section{By $D_{R}$. C. H. IADDINGTON}

$T$ HERE are two main spheres in which biology is of practical importance to society. One is medicine in the widest sense, which it would perhaps be more accurate to call human biology, and the other is food production or agriculture, also in the widest sense.

I do not propose to discuss the first of these fields in any detail, although new discoveries and new applications of old discoveries are always being made. Among recent new discoveries one may perhaps mention the bacteriocidal and bacteriostatic substances which are now being obtained from lower organisms. Penicillin, extracted from a mould

* Substance of a lecture delivered at the Royal Institution on February 12 . 
related to the ordinary bread mould, is being investigated at Oxford and elsewhere and seems likely to prove one of the most powerful aids in dealing with infected wounds, a matter of the greatest importance at the present time. It may, however, be rivalled by gramicidin, a substance prepared by American workers from certain types of bacteria which grow in soil; but perhaps the more optimistic view will prove justified and the two substances be found to attack rather different kinds of germs and thus to supplement each other. As an example of a new technique of utilizing old biological knowledge, one may mention the treatment of various diseases, chiefly cancer in some of its forms, by radioactive substances artificially prepared with the aid of new physical apparatus such as the cyclotron. Radiophosphorus and radio-iodine are differentially absorbed by different tissues in the body ; their radioactivity causes the destruction of the tissues in which they become located and the surgeon can in this way bring about a localized inhibition of particular tissues which are proliferating too rapidly.

But the great tasks of medicine in the immediate future are concerned with the application of knowledge which we already possess. These tasks can be summarized under three heads: first, the attainment in practice of optimal standards of nutrition, of housing, of industrial hygiene, and so on ; secondly, the conquest of tropical diseases and the improvement of the health of tropical populations until they have an equal chance with the peoples of the temperate zones to play their part in world civilization; and thirdly, a task in which social biology must collaborate with political and other agencies, is the reversing of the general fall in the reproductive-rate in industrial countries. New discoveries may, and very probably will, be made which will assist in the carrying out of these tasks, but the main problems are certainly the administrative and political ones of applying existing knowledge.

When we turn to the field of food production we find a great body of existing knowledge which is in process of being put into practice. Such developments of farming practice as the system of ley-farming and the increased use of silage are examples. But there are also a number of biological discoveries which may have very revolutionary effects on the whole of our food production system, and it is primarily a summary of these more far-reaching possibilities that I propose to discuss.

We may mention first some new uses for old crops. Straw is bound to be produced in large quantities along with any cereal crop, but, except for some oat straws, it is itself of little value for feeding animals. It has recently been shown that a treatment with caustic alkali breaks down the hard tissues of the straw sufficiently to allow of its being digested by cattle, and a very considerable new source of feedingstuffs has thus been placed at the farmer's disposal. A more striking innovation would be the direct use of grass protein for human consumption. Grass is much our biggest crop; we produce about 60 million tons a year. It is too full of indigestible fibre to be eaten by man in the raw state, and the methods by which we use it are still those which were invented in the Stone Age; we feed it to cattle and sheep and ourselves eat the beef, mutton, milk, etc., which they produce. They can, it is true, digest the fibres with which the human intestines cannot deal, but they are relatively inefficient in making use of the proteins. Now it is comparatively easy to grind up the grass and squeeze out some 30 per cent of the protein for our direct use. The remainder of the protein remains with the fibres, the whole mass still representing a better cattle food than ordinary hay. The technical problem of making the grass protein into a really attractive and palatable product should not long remain beyond the capacities of our biochemists. When it is pointed out that the total quantity of grass protein grown in Great Britain is something like ten times our normal protein requirements, the potential importance of the direct utilization of even a small fraction of it requires no further emphasis; but the economic and agricultural problems of employing the process on a large scale require further study.

Let us consider now some new technical possibilities in the cultivation of our crops. Much publicity has been given recently to tank-culture or hydroponics. By this is meant the cultivation of plants in culture solutions the concentration and composition of which can be accurately controlled. Such methods are, of course, by no means innovations in the laboratory; it is only their utilization on a large scale for commercially grown greenhouse crops which would be a new departure. It does not, however, seem by any means certain that this technique has any great advantages, at least in the climate of Great Britain, over the method of soil sterilization which was introduced some years ago and is now becoming rery widespread.

Another technical innovation from which much can be expected is the use of the recently discovered plant hormones. Knowledge in this field is still growing rapidly but we already understand something of the part played in the growth of a plant by very small quantities of certain essential substances, some of which are in fact identical with the vitamins which we hear so much about in our own diet. Some of the hormones are already quite widely employed to encourage the rooting of cuttings; but there are many more possibilities emerging in the laboratories of the world -for example, the growing of long-fibred stems in textile plants such as flax and hemp, the production of seedless fruits from unpollinated flowers treated with suitable hormones, the control of the opening of flower buds until the danger of severe frost is past, and so on. Moreover, new hormones are still being discovered, some, such as a new pollen extract recently described by the United States Department of Agriculture, controlling growth, while others are concerned with various other phases of a plant's development.

These studies have not yet been brought into relation, although they soon must be, with another very important development which has arisen in practical crop management. Russian biologists in particular have devoted great attention to the investigation of the time of ripening of plants, with the view of developing types which can either survive their rigorous winter or which can crop in a single year after planting in the spring. They have developed a rather elaborate theory of the succession of various phases in a plant's development, which they distinguish sharply from its growth. In general a plant first passes through a temperature phase, in which it requires a certain length of exposure to particular low or high temperatures; this, they claim, is succeeded by a light phase, in which the plant must be subjected to particular conditions of long or short daily periods of illumination. The practical application and indeed the practical basis of this theory is 
the technique known as vernalization, in which the germinated seeds are artificially given the treatment needed to complete the first phase of development before being sown. Thus a winter variety of wheat, which is normally sown in autumn and lies in the ground over winter, starting to grow in the following spring, may be artificially cooled for the required time and then planted in the spring to crop in the same year. Such methods would be of some value even in England and may be of very great importance in countries with the severe climatic conditions of Soviet Russia, where many million acres have been sown with vernalized seeds. Workers in other countries are not so convinced of the practical value of the method, and the details of both theory and practice are still under discussion. But there seems little doubt that the basic phenomena are quite real and that our understanding of the matter will rapidly become much more profound. It has already been shown that, in certain plants, substances capable of diffusing from a stock into a grafted scion are concerned in controlling whether flowering takes place in the first or second year, that is, with or without subjection to cold and short daylight, and it therefore seems most probable that the whole vernalization question will in time be brought into relation with the discovery of plant hormones already mentioned.

Some Soviet authors have claimed that a single vernalization treatment is sufficient to alter the hereditary constitution of the plants, so that its effects are permanent. Most biologists are likely to doubt the possibility of such a direct action, but it may well be that the Soviet workers have actually discovered a phenomenon of great importance. Since the development of a plant, as we have seen, is profoundly influenced by the early treatment of the seed, a single artificial treatment which causes the plant to mature at an abnormal season may have some effect on future generations owing to the altered conditions under which the seed will be formed. Similarly, another phenomenon on which the Russian scientific workers have laid great stress is the effect of a host plant on the hereditary constitution of a graft; again, the effect may not be a direct one on the hereditary elements as normally understood, but it may be a real phenomenon based on the transmission of something in the nature of a virus.

This brings us to the subject of plant-breeding, one of the fields in which the most spectacular advances are likely in the near future. The breeding of disease-resistant varieties, which, for example, trebled the yield of sugar cane in Louisiana between 1926 and 1929, will probably score some new successes but it cannot be considered a new technical advance. On the other hand, the practical employment of hybrid vigour is a development of the last few years in maize growing. At the present time something like twenty-five million acres are sown with hybrid corn in America, and increases in yield average about 20 per cent. Probably there are similar benefits to be obtained in other crops. The John Innes Horticultural Institution, for example, has prepared hybrid tomato seed with very considerably enhanced productivity.

The most important advances, however, are likely to come from two fields which are still being intensively investigated. The first is the study of the wealth of forms available in Nature for our use. Until recently the range of types employed by the plant breeder has been getting progressively narrower as he concentrated on the improvement of ever more specialized varieties. But it has been realized that much may be gained by the introduction of new hereditary material and it has come as something of a shock to discover how rich is the stock of forms available. Not only are there very numerous local varieties of cultivated plants, each probably with many defects by modern standards although with one or two points of advantage, but there is also a hitherto unexpected variety of wild forms related to the cultivated species. For example, all the cultivated potatoes of the Old World derive from a single species and probably from a very few individuals. We know now at least thirty species, forming a polyploid series, all of which were thought worthy of cultivation by some tribe in South America, and there are also related wild species. They include frost-resistant and short-day forms and varieties resistant to various diseases. It is not too much to hope that we shall fairly soon be able to develop potatoes suitable for the Arctic and for the tropics. The profound results of such a spread of the potato belt do not need to be emphasized.

The second major source of new varieties may be found in the very recent technique of artificially doubling the number of chromosomes in hybrids, thus rendering them fertile and comparatively stable in hereditary constitution. Nearly all our most important crop plants have arisen by a chance occurrence of a similar process in Nature. Now that we have discovered substances, the most important of which is the drug colchicine, which allow us to double chromosome numbers with fair regularity, it is almost inconceivable that we shall not be able to manufacture completely new types of plants of the greatest importance. It is too early as yet to name any examples with complete confidence, but the hybrids of wheat and rye, and of wheat and couch grass may be mentioned as instances of promising beginnings.

An advance of another kind is the recent success in hybridizing yeast. Until recently it was thought that if a single yeast cell was isolated it must give rise to a pure colony. But single yeast cells may be either haploid with one of each kind of chromosome or diploid with two. In the latter case haploid cells will be formed during the growth of the colony and the segregation of different types will occur, so that the final colony is mixed. Winge, in Denmark, has succeeded, by a fine technique of micro-manipulation, in isolating single haploid cells, hybridizing them and finally isolating the segregants from the hybrids. This is the first application of modern breeding methods to some of man's oldest plant collaborators, his assistants in the manufacture of such staples as bread and beer.

If we turn now to the animal field, many of the methods which seem to promise best among plants do not appear very feasible. Thus there are great technical difficulties in making such a full use of hybrid vigour, although some promising results have been obtained with fowls. Again, only the very first steps, in which I have myself shared, have been taken towards doubling the chromosome number in animals, and the difficulties to be surmounted before we can produce fertile hybrids in this way are rather overpowering in prospect.

Perhaps the most importent new technique which is just passing from the laboratory into general practice is that of artificial insemination. If the 
sperm of a selected male is artificially introduced into the female, the greater degree of control over the process makes it possible to employ much smaller quantities than Nature provides, and the number of offspring which can be obtained from a single male may therefore be multiplied some hundreds of times. This makes it possible to ensure that only the very best animals are used as fathers and the constitution of poor stock may thus be quite rapidly improved. The method has already been tested out on quite a wide scale and it has been found possible to send the sperm of desirable males for very considerable distances by air. The method has a very great part to play in the immediate post-war world when we are confronted with the problem of restoring the scorched earth of eastern Europe.

A development of the technique of artificial insemination which seems likely in the next ten or twenty years is the artificial determination of sex by the separation of male- and female-determining sperm. Such a possibility is, of course, a favourite theme of all kinds of charlatanry and psuedo-science. But some recent work, particularly in the U.S.S.R., indicates a serious possibility that the problem will be solved by the method of electrophoresis, that is to say the passage of an electric current through a suspension of sperm, causing an accumulation of the female-determining sperm at the anode and of maledetermining at the cathode. There are still many technical details to be worked out, such as the most favourable salt solutions, temperature, etc., but it would be a bold man who denied the possibility of a fairly early solution of the problem. The importance of such a method for the dairy and poultry industries would be profound, but its application to human affairs obviously presents aspects of great difficulty.

It would be in the highest degree desirable to bring about a similar increase in the reproductive capacities of the females of domestic animals. This may be too difficult a task, but some increase can already be envisaged. The administration of suitable hormone preparations, for example, can bring a female into the breeding condition at a time of year when she would normally not be ready to receive the male. Some success has already been achieved in obtaining in this way two crops of lambs a year instead of one. Again, when a female is ready to breed the number of ova produced, and thus the number of young born, is rather restricted in many of our domestic animals, and treatments are being worked out which should make it possible to cause the formation of more ova. This will, in the first instance, enable us to cause a regular production of twins by our beasts. For particular purposes of breeding from exceptionally favourable females it may prove possible, by a technique which has already been used in rabbits, to increase the number of ova many times and to transplant some of them to the uteri of other females, which would then act as foster-mothers from the very earliest stages of the animal's development.

The control over developmental processes given us by the use of hormones may play a part in several other ways. We are beginning to have some understanding of the role of such substances in lactation. We know there are hormones which control the initial development of the mammary glands as well as the intensity of their secretion, and again it has proved possible to influence to a significant degree the content of milk in several important constituents. All these investigations, still essentially laboratory matters, are likely fairly soon to reach the point where we can begin to apply them in practice, when they may open up great possibilities of control over our milk supply, particularly in the difficult winter months.

A somewhat more speculative possibility is the employment of hormones for the control of size. In some animals at least, for example, the rat, it has been possible to obtain considerably increased growth by suitable hormone injections. Further, the embryo of a mammal is in a somewhat similar position as regards its mother as the plant grafts mentioned earlier; an effect exerted primarily on the mother may, by influencing the early development of the foetus, produce an alteration which will affect the development of the next generation of young and thus be transmitted potentially for ever. That such an influence of the mother on her offspring of the first generation is a possibility is known from crosses between large and small breeds of horse, in which the size of the mother has a great effect on the size of the foal. An effect in more remote genorations has been suggested by some workers using extracts of the thymus gland on rats. The matter is still very uncertain, but if it can he put on a firm basis very important results might be obtained. A further and still more speculative possibility may perhaps be worth mentioning; it has been claimed that the very early administration of growth-promoting extracts has à differential effect on those organs which develop most rapidly at early stages, particularly the brain. It is not clear whether the swollen-headed rats so produced were any cleverer than usual, but the possibility of such an effect may be worth considering, if only as a day-dream to solace the despair to which most educators are from time to time reduced. Let us hope, however, that man is already intelligent enough to use, for his benefit and not only for his destruction, the gifts which science offers, without waiting for a hormonally induced enlargement of his brain.

\section{OBITUARIES}

\section{Sir Francis Younghusband, K.C.S.I., K.C.I.E.}

Sir Francis Younghusband, whose death occurred on July 31, was an outstanding example of that rather rare combination-a philosopher and a man of action. A passionate admirer of the beauties of Nature he had, almost from childhood, pondered and studied the mystery of living things-their origin, their evolution and their spiritual significance-and during his later years he embodied his thoughts and his philosophy in a number of books and papers.

His more practical activities as a man of action found their chief outlet shortly after he arrived in India as a young officer of cavalry. His first journey, in 1886, at the age of twenty-three, was made in company with Mr. H. E. M. James of the Bombay Civil Service, and Mr. H. Fulford of the Chinese Consular Service, when they travelled through large areas of Manchuria and explored in particular the range known as the Long White Mountain. An account of this journey was given by Mr. James in his book of that name, in which he pays tribute to the energy and ability of his young companion, who made himself invaluable in a variety of activities-surveying, the collection of entomological and botanical specimens, sketching, and so on. These wanderings 